\title{
COVID-19 Pandemic: Rethinking Strategies for Resilient Urban Design, Perceptions, and Planning
}

\author{
Sadia Afrin ${ }^{1}$, Farhat Jahan Chowdhury ${ }^{2}$ and Md. Mostafizur Rahman ${ }^{1 *}$ \\ ${ }^{1}$ Department of Environmental Sciences, Jahangirnagar University, Dhaka, Bangladesh, ${ }^{2}$ Environment, Asian Development \\ Bank, Bangladesh Resident Mission, Dhaka, Bangladesh
}

From the beginning of the COVID-19 crisis, the scientific community has been continuously trying to assess the virus, its socio-environmental impacts, regulatory/adaptation policies, and plans. The emergency is to develop pandemic-resilient city planning and management in order to tackle the infectious diseases during COVID-19. Such development includes the reframing of unsustainable urban patterns, hazards, and social inequalities to be prepared for the emerging cases. In this study, we focus on the assessment of disaster risk management (DRM), which will help to develop pandemic-resilient urban strategies (response, mitigation, and preparedness phase) through analyzing previously published literature. Short- and long-term recommendations for pandemic resilience urban planning and design have

\section{OPEN ACCESS}

Edited by:

Kh Md Nahiduzzaman,

University of British Columbia

Okanagan, Canada

Reviewed by:

Muntasir Billah,

Lakehead University, Canada Chandana Siriwardana,

University of Moratuwa, Sri Lanka

*Correspondence:

Md. Mostafizur Rahman rahmanmm@juniv.edu

Specialty section:

This article was submitted to

Sustainable Infrastructure,

a section of the journal

Frontiers in Sustainable Cities

Received: 15 February 2021

Accepted: 03 May 2021

Published: 14 June 2021

Citation:

Afrin S, Chowdhury FJ and

Rahman MM (2021) COVID-19 Pandemic: Rethinking Strategies for Resilient Urban Design, Perceptions, and Planning.

Front. Sustain. Cities 3:668263. doi: 10.3389/frsc.2021.668263 also been provided. In the response phase, implementation of the smart and resilient city design and policies has been highlighted to identify disease transmission. In the mitigation phase, new technological approaches can be adopted for better management of present and future pandemics. The physical (urban access, infrastructure, environmental factors, and land use patterns) and non-physical (socio-cultural, governance, and economic factors) aspects of resilient urban strategies have been focused, which may help to develop understanding of health- and disaster-related risks in pandemic. In the preparedness phase, proactive measures such as capacity building of people toward any outbreak and different simulation processes (models of transmission pattern) can be adopted for future pandemics. We also discuss about the enhancement of urban resiliency in housing, public spaces, and cities that may bring the effective outcome of DRM framework to combat pandemic. The study focuses on the major lessons that can be adopted for post-pandemic urban resilient planning related to disaster management and climate change adaptation, preventing extensive challenges of sustainability apart. In the following months and years, it will be difficult to assess various changes to develop urban planning and design in the post-COVID-19 world. However, this study expresses the possibility of creating good opportunities for policymakers and city planners to undertake significant transformative and advanced actions during the three different phases of DRM. This study presents a novel approach to delineate the scope of DRM framework in achieving more resilient cities $(\mathrm{RC})$ to tackle future pandemics. This study will also crucially help the planners and decision-makers in better assessing and addressing the strategic and resilient urban design and planning approach in future.

Keywords: pandemic resilient urban strategies, disaster risk management, physical and non-physical dimensions, recommendation for future urban planning and design, adaptation, planning 


\section{INTRODUCTION}

Cities are the central point of technological and economic growth worldwide. Most of the people around the world live in cities. Pandemic is referred to as a new disease that spreads across the countries in the world. A pandemic, even on smaller scale, can kill millions of lives (Osterholm, 2005). According to Mills et al. (2004), there have been three fatal pandemics in the past 100 years which were in 1918, 1957, and 1968. COVID-19 has affected the economic and social aspects severely. The first coronavirus (COVID-19) confirmed cases were identified in December 2019 in Wuhan, Hubei Province, China (Ji et al., 2020). Then, this virus has swept across many countries throughout the world (Lu et al., 2020). Due to the pandemic, a huge burden has been imposed on the lives of people and the economy also. According to Sharifi (2020), several research have been done in order to assess the impacts of various disasters in urban areas, along with necessary planning, adaptation, and design for building up resilience on a larger scale. Cities are responsible for the higher pandemic transmission rate because cities have rapid urbanization, huge growth of population, and high level of transportation usage and contribute $80 \%$ of the global GDR (The World Bank Annual Report, 2019). Due to the increased number of smart technologies such as the Internet and so on, we were able to face this situation in a prudent manner, but now cities must be more resilient than before. Especially in developing cities, adopting a resilient and smart city planning and design is compulsory. US, UK, Italy, Germany, the Netherlands, France, Belgium, and Spain were severely affected in the first 3 months after the initial COVID-19 transmission. These countries are continuously trying to take feasible measures to confront the pandemic effectively since the outbreak. For future pandemics, the cities need to adopt a technology-driven approach through following smart city framework (Kummitha and Crutzen, 2017) and strategies of disaster risk management (DRR) framework. This can be achieved by using a human-driven approach and a top-down approach which will encourage the citizens to develop and enhance their capital through adopting necessary smart technologies in cities (Mora et al., 2017). Research on pandemic-affected cities primarily reflected that marginalized people were the most vulnerable (Wade, 2020). The emergence of COVID-19 has resurrected the attention on urban vulnerability to pandemics. Various stressors, such as climate change and wildlife habitat disturbance, can intensify future pandemics' frequency. To face this emergency, knowledge on pandemic pattern, dynamics, and how they affect cities, along with the required preparation, response, and adaptation measures, is indispensable (Connolly et al., 2020a). Shedding light on this matter, this study focuses on better understanding the pattern of how pandemics affect cities, the necessary actions to reduce the impacts, and increased urban pandemic resilience.

In this study, strategies for resilience urban planning and design indicate to equipping urban areas to encounter shocks and stresses from pandemic crisis in the future. Resilience itself possesses strength and resolving power. A resilient urban area takes into account suitable form and physical construction and infrastructure that are more robust for upcoming social, economic, and physical shocks and challenges resulting from a pandemic. To what extent we can achieve it depends on ongoing processes such as future proofing and so on. Future proofing may not lead to complete proofing, but it can significantly reduce potential shocks and resulting impacts, bringing a more robust concept of resilient urban planning. Few principles must be followed to create resilient urban planning and design, such as the following:

1. transit supportive development,

2. conservation of energy resources and enhancement of vibrant areas which will act as significant elements of suitable housing and community structure,

3. enhancement of the natural health system criteria, including the effectiveness of the environment and health safety in urban areas,

4. enhancement of efficiency and safety of industrial systems including transportation, construction, and infrastructure to augment energy efficiency and thus reduce the overall environmental footprint,

5. active participation of community members from all sectors to develop convenient plans,

6. design and distinct planning of critical infrastructure criteria and systems for the safety of the residents' lives, with the aim of equal level of durability and redundancy with the growing environmental, economic, and socio-cultural shock and stresses arising from the pandemic situation, and

7. development of decreased servicing cost-associated building types and city forms to reduce environmental footprints.

Pandemics have affected cities before; therefore, some literatures related to pandemics before the novel COVID-19 are available online (Matthew and McDonald, 2006). According to scientific articles of the past few months, it is clear that much research have been conducted for a better understanding of the patterns of pandemics and tried to find out the unanswered aspects of this pandemic. Most of the research have focused on the treatment and diagnosis of this virus (Harapan et al., 2020), such as this virus that can cause pneumonia and several kinds of sickness, thus affecting the upper respiratory tract and nervous system. This pandemic can also be a cause of death for people who are suffering from severe health conditions. This virus has the capability to transmit from one human to other humans, so a certain kind of health safety should be maintained. In order to combat this pandemic situation, the World Health Organization (WHO) manifested that the government should augment a surveillance system as quickly as possible to assess the isolation criteria of infected persons and to maintain quarantine measures (Heymann and Shindo, 2020). In the cities, most developed and rigorous surveillance were imposed in the first 3 months of the virus' outbreak. The Chinese government followed the technological approach and kept the transmission in control, but in western countries, a human-driven approach was followed to combat the pandemic. In order to control the pandemic dynamics, social distancing, which involves cutting down interactions among citizens, is quite challenging (Mollalo et al., 2020) and has impacted urban life, form, meaning, and activity. This study reflects the impacts 
of both technological and human-driven approach in virus transmission control. We also discuss how resiliency can be enhanced by technology's contribution, though the participation of humans with technology hinders the potential of it. For that, smart technologies can be implemented in both social and political contexts, while the approach that needs to be adopted has been discussed considering both the practical and theoretical implications of resilient urban planning and design. It also highlights the limitations of the approaches and suggests scopes for further research. Following the ongoing impacts, significant attention has been provided on how the cities are being affected by the pandemic and their response to it. For such an alarming issue, a lot of research on COVID-19 and cities have been published. Thus, literature review has been done to reflect the existing knowledge and limitations, though few studies have been successful in highlighting such issues. Despite the gaps, the main features of this study are to develop a better understanding of the major impacts on cities due to the pandemic and reflect major learnings and recommendations that can be undertaken for post-pandemic resilient urban planning. For this work, previous literatures on these topics have been followed. Therefore, better assessment of the issues that the pandemic has imposed on cities should be addressed and rigid measures must be followed in order to develop more pandemic-resilient cities (RC).

Sendai Framework for Disaster Risk Reduction (UNISDR U, 2015) from 2015 to 2030 and the Global Assessment Report (UNISDR, 2015) demonstrated a new holistic approach to establish resiliency for disaster risk management (DRM) though focusing human health and development goals resiliency. During the past few years, the DRM resilient concept has been constructed, thus providing a wide ecological resilience approach (Wallace and Wallace, 2008). The DRM approach focuses on effective strategies for preparedness, response, and mitigation (Kinsman et al., 2018; Lawton and Nahemow, 2019). Reformed approaches of preparedness, response, and mitigation are essential strategies, though they can cause such uncertainties in achieving success in high-density populated areas and in developing countries (Bell et al., 2009). Rivera et al. (2020) described the three phases of DRM (preparedness, mitigation, and response):

- Preparedness phase primarily focuses on the enhancement of capacity building of people and the response capacity of cities against any outbreaks.

- Mitigation, also known as the prevention phase, refers to the structural and non-structural measures and activities to be adopted to reduce the negative impacts of epidemics and pandemics.

- Response phase can be defined as the structure of public assistance and emergency services during or immediately after the pandemics in order to minimize health impacts through limiting the disease transmission rate along with confirming public health safety and focusing on the essential needs of the affected individuals (Djalante et al., 2020).

Lak et al. (2020) and Carmona (2014) jointly demonstrated resilient urban planning, design, and processes for constructing a pandemic-resilient form through the evaluation of development, communication, and control measures. However, this study highlights a conceptual framework of DRM approach in a unique manner for a pandemic-resilient urban strategy by incorporating resilience in urban planning and design for the first time considering the ongoing COVID-19 crisis. Possible recommendations are provided in three levels (housing, city, and public places) to increase the efficiency of response, mitigation, and preparedness phases against epidemics and pandemics in the future.

\section{METHODOLOGY}

The main methodology of this study is to follow the relevant publications which include papers and articles in broadly used database of scientific articles such as Science Direct, PubMed, Web of Science, and SCOPUS database. The search criteria were followed, broadly covering the reasonable research design that focuses on urban areas and their planning and design for achieving resiliency for post-COVID-19 world. Around 43,071 articles related to COVID-19 were found until February 10, 2020, and it is expected to increase in the future. The keywords for the search criteria were as follows: "C-O-V-I-D-19- R-E-S-I-LI-E-N-T- U-R-B-A-N- P-L-A-N-N-I-N-G," "C-O-V-I-D-19 -\&I-M-P-A-C-T-S- O-N- C-I-T-I-E-S," and "C-O-V-I-D-19- C-I-TY- P-L-A-N-N-I-N-G -\&- D-E-S-I-G-N.” The screening process reflected that several articles are not related to urban design, planning, and management criteria. Therefore, we excluded these types of papers, although many articles include cities referring to Wuhan as the source point of the pandemic or other urban areas in which certain medical trials had been taken. Accordingly, 62 articles were filtered from the database after checking the abstracts, followed by different sections depending on certain thematic areas (Figure 1).

During the process, we also monitored the database to receive new publication updates. The selected papers were carefully reviewed to collect necessary information regarding our purpose for the proper analysis to be reflected in the following section. For the specificity of selected papers, data were collected in Excel sheet based on the environmental and socio-economic impacts, geographical focus, and necessary lessons. At each stage, the authors reviewed the articles several times to assure the accuracy of the collected information. For the review, these information were then used.

\section{RESULTS AND DISCUSSION Resilient Urban Design and Planning Approach}

The world has faced several challenges in 2020, which include social unrest, severe climatic events such as wildfire, economic shock, and so on during the COVID-19 pandemic. The COVID19 pandemic has shifted the perception of local governments to the emergence of incorporating resilience into their response and recovery approaches. It has also raised a pivotal issue 


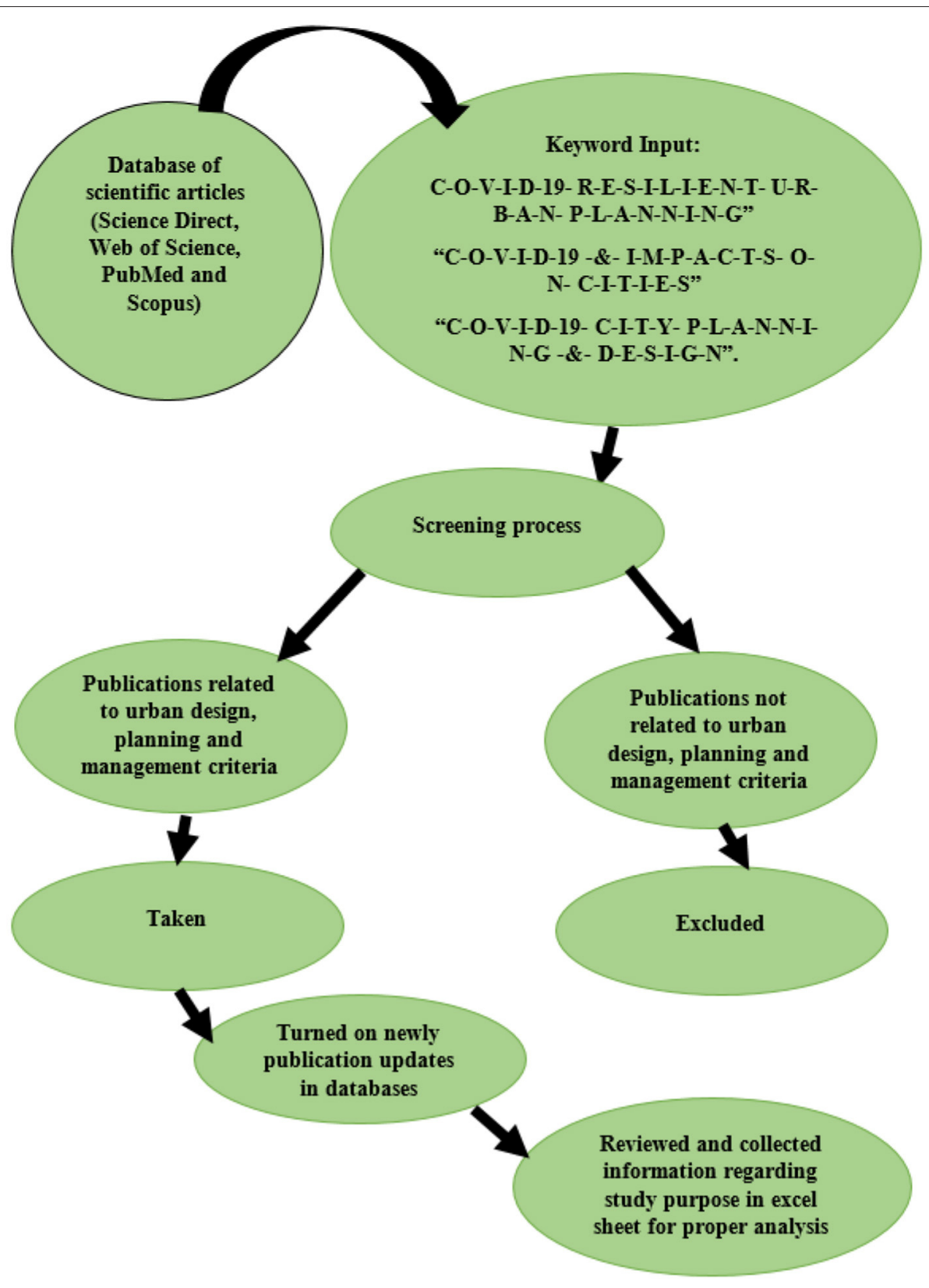

FIGURE 1 | Methodology of the study.

on changing perception toward resilience, focusing on major lessons learned to make communities firm against extreme coming shocks, and economic, environmental, and social impacts (Table 1). According to the 100 Resilient Cities (100RC) network, multiple-benefit approach must be integrated in the present design and planning to combat high stresses and shocks. Urbanization is continuously trending globally, and social challenges are also increased, to be addressed by city-level governance. Existing literature highlights the evidence that strategies of urban governance are resilient urban form, predisaster planning, primary healthcare facility increase, early warning system, and collaboration of actors from different sectors, where policymakers and stakeholders work as a median to take effective and sharp response criteria for disease outbreaks and pandemics in urban areas (Duggal, 2020; Shammi et al., 2020; Thoi, 2020). Various urban designs and forms can create a significant impact on the pandemic dynamics, though existing literatures are not well-explored in this issue. This pandemic has highlighted some issues which involve the establishment of more resilient urban development. Because of the mass interaction, the highly populated areas have the potential to become hotspots for the fast spread of any pandemic. According to Hamidi et al. (2020), a significant positive relation between density, COVID-19, and mortality rates was not clearly found. 
TABLE 1 | Major areas focused by pandemic and lessons learned for pandemic-resilient urban planning and design for post-COVID-19 world (modified after Sharifi, 2020).

\begin{tabular}{|c|c|c|}
\hline Thematic area & Issues were identified by the pandemic & Lessons for post-COVID-19 world \\
\hline Economic impacts & $\begin{array}{l}\text { Vulnerability increased due to identical economic structure } \\
\text { Due to the pandemic, poor and marginalized people are } \\
\text { disenfranchised for the economic downfall } \\
\text { Cities are being vulnerable to several kinds of crisis for the global } \\
\text { supply chain }\end{array}$ & $\begin{array}{l}\text { Economy pattern in urban areas must be diversified } \\
\text { Poor and marginalized people must be supported by relief programs } \\
\text { during the pandemic } \\
\text { Shift to local supply chain to increase self-sufficiency to face economic } \\
\text { downfall by the pandemic or any disastrous events }\end{array}$ \\
\hline Social impacts & $\begin{array}{l}\text { Highlighted the existing problems in a new way } \\
\text { Inequalities creating challenges and may cause the spread of the } \\
\text { virus } \\
\text { In congested areas like slums, social distancing measure is raising } \\
\text { challenges }\end{array}$ & $\begin{array}{l}\text { Inequalities must be contracted to better address the vulnerable } \\
\text { groups and their needs } \\
\text { Slums need to be upgraded } \\
\text { Mechanism of economic assistance needs to be introduced with social } \\
\text { distancing measures to make it effective } \\
\text { Response and recovery strategies must be enhanced }\end{array}$ \\
\hline Smart city approach & $\begin{array}{l}\text { Smart solutions have supported response and recovery strategies } \\
\text { to act effectively such as identifying and separating infected } \\
\text { people reducing human-to-human thus to abate human contacts } \\
\text { everywhere } \\
\text { Technological approaches have contributed successfully in } \\
\text { controlling the virus, though certain privacy protection and } \\
\text { transparency concerns have been raised }\end{array}$ & $\begin{array}{l}\text { For effective response and recovery measures, certain permits need to } \\
\text { be provided to the public, making safe access to actual and accurate } \\
\text { geo-referenced Geographic Information Systems data } \\
\text { Human-oriented approaches should be developed and made suitable } \\
\text { for public empowerment } \\
\text { Technological approaches should not be misused, affecting privacy } \\
\text { issues } \\
\text { Both of these approaches can better address in controlling the } \\
\text { pandemic through information sharing and simplifying co-ordination }\end{array}$ \\
\hline $\begin{array}{l}\text { Existing capacity and } \\
\text { limitations of cities }\end{array}$ & $\begin{array}{l}\text { Due to lockdown, regional movement has been restricted, which } \\
\text { is neglecting the needs of the migrants }\end{array}$ & $\begin{array}{l}\text { Migration networks should be established } \\
\text { Origin and destination networks can be established while planning } \\
\text { transportation options which can help self-quarantined migrants to } \\
\text { move safely to their destinations, thus reducing the city load by both } \\
\text { ensuring people to stay at safe places and fulfilling their essential needs }\end{array}$ \\
\hline $\begin{array}{l}\text { Urban planning and } \\
\text { design }\end{array}$ & $\begin{array}{l}\text { Enhanced public transit connectivity acts as a risk factor which } \\
\text { can increase the transmission rate of the virus } \\
\text { Negatory notions were attributed due to the pandemic } \\
\text { Density and other factors were found responsible for the } \\
\text { transmission of the virus } \\
\text { Social distancing measure after a certain period was found quite } \\
\text { challenging due to lack of greener open spaces }\end{array}$ & $\begin{array}{l}\text { Efficient mobility restraint should be enacted in order to control the } \\
\text { transmission risk of the virus through different transit modes } \\
\text { Efficient public transport focusing on reducing the public health risk } \\
\text { needs to be established } \\
\text { Improved public infrastructures and amenities should be focused } \\
\text { unitedly to make high-density populated areas less vulnerable to } \\
\text { disruptive events } \\
\text { Planners should improve the development of urban areas firmly by } \\
\text { flourishing them } \\
\text { More open and greener spaces should be developed for pedestrian } \\
\text { and so on to be better prepared for future events }\end{array}$ \\
\hline
\end{tabular}

It was found that, in highly populated areas, the virus-related mortality rates are relatively low. On the other hand, according to Boterman (2020), a negative relationship between density and infection rate was found in densely populated and urbanized countries such as the Netherlands. Lin et al. (2020a) also manifested that the density in Wuhan, China, is the key factor for the spread of COVID-19. Therefore, after adjusting the former features, the linear relationship between spread rate and population density disappeared, and it was also found that there were low spread rates in high-density areas, although a contrast in view exists. In China, how the transmission rate impacts on certain socioeconomic and environmental characteristics was investigated in two levels by Qiu et al. (2020). That study indicated that population density does not have any specific relationship with COVID-19 transmission rate initially, but the scenario has changed on the second phase. Public health criteria and resource sharing are two key factors that are responsible for minimizing social interactions and creating a change in the last phase. On the contrary, Ren et al. (2020) investigated that, in countries like Beijing and
Guangzhou, COVID-19 infections occurred in high-populationdensity areas. In countries like Italy, a higher transmission rate was shown in larger populated areas (Cartenì et al., 2020). This reflects that physical distancing is far more challenging in highly populated cities, which involve more crowded places. Accordingly, density and other factors such as development state, necessary prevention and response measures, and public health infrastructure along with proper sanitation and social distancing approach must also be highlighted. High-populationdensity areas must be prepared and should have access to necessary resources in order to respond and impede the virus from spreading (Connolly et al., 2020b). Meanwhile, low-density suburban and peri-urban territory have confined access to resources and can be exposed to new viruses and diseases, and due to excessive natural resource encroachment by humans, these diseases can be increased through increased interaction between human and wildlife (Connolly et al., 2020b). Urban area size, along with other variables such as connectivity, is the contributing factor that affects the early stage of any epidemic outbreak (Lin et al., 2020a; Stier et al., 2020; Wu et al., 2020; 
TABLE 2 | Short- and long-term recommendations for pandemic-resilient urban planning and design.

\begin{tabular}{|c|c|}
\hline Preventive measures & Recommendations \\
\hline $\begin{array}{l}\text { Zoning regulations: This regulations control land } \\
\text { use, density pattern, building design, and } \\
\text { configurations, thus indicating the place and } \\
\text { procedure of new population growth }\end{array}$ & $\begin{array}{l}\text { Long term: } \\
\text { - Physical planning of urban areas should be revised } \\
\text { - For ensuring resilient buildings, refinement of building codes is necessary } \\
\text { Short term: } \\
\text { - Disinfection protocols needed to be followed with maximum occupancy in commercial and recreational facilities } \\
\text { - Planning policies need to be more flexible } \\
\text { - Reorganization of buildings and spaces to enable people to work safely during the pandemic } \\
\text { - Certain permits must be repurposed for sectoral impacts, which include transforming damaged retail centers for } \\
\text { new residence purposes } \\
\text { - Multi-use buildings should be developed in order to reduce traveling from district to district for a single purpose } \\
\text { - Make people self-sufficient through adequate provision of healthcare services } \\
\text { - Incorporation of digital infrastructure and technological approaches to help cities grow, making them more safe }\end{array}$ \\
\hline Informal settlement & $\begin{array}{l}\text { Long and short term: } \\
\text { - Slum redevelopment } \\
\text { - Change the pattern of land ownership for greener and open space } \\
\text { - Integrate urban fabric strategy }\end{array}$ \\
\hline Inclusive planning & $\begin{array}{l}\text { Long and short term: } \\
\text { - A participatory, holistic, and sustainable approach should be developed for community re-development to bring } \\
\text { out possible solutions to the crisis } \\
\text { - Long-term economic recovery plans must be focused, such as job creation, promoting the use of more efficient } \\
\text { and green technologies, e.g., renewable energy, and addressing market failures such as mispresented subsidies } \\
\text { which act as barriers for long-term economic growth } \\
\text { - Combined solutions can be developed, e.g., using nets to reduce plastic pollution, plastic recycling, defunct well } \\
\text { reuse for aquaculture, and so on }\end{array}$ \\
\hline Resilient urban features & $\begin{array}{l}\text { For future studies, there is a need to highlight the issues of qualitative studies on pandemic-resilient urban features } \\
\text { through the collaboration of urban health experts to establish resilient urban planning and design. Furthermore, } \\
\text { field and quantitative studies can explore the linkage between resilient city features where disease transmission } \\
\text { and pandemics, e.g., COVID-19, have occurred in cities }\end{array}$ \\
\hline
\end{tabular}

Xie and Zhu, 2020). Hamidi et al. (2020) also investigated and found that connectivity acts as a risk factor for COVID19 in developed countries like the US, and these countries provide more emphasis on connectivity in order to explain the virus transmission dynamics. This highlights that, in larger cities, policymakers must implement such presumed protection measures (Stier et al., 2020). Therefore, further study is needed to better assess the possible relations between urban area size and outbreak of infectious diseases prevalence in urban areas. On the contrary, in Bangladesh, due to the absence of previously established planning and emergency plans, cities are facing difficulties to respond to the emergency effectively. As a result, they are unsuccessful in properly assessing the risk, situation, and healthcare system capacity and in adopting necessary measures through the joint actions of multiple sectors and policymakers (Shammi et al., 2020).

However, there is a significant absence of exploratory evidence on existing effects of city design and public spaces on the spread of infectious diseases. It also highlighted that urban areas need to allocate more open or public space for active transit modes (Medda, 2012). This involves redesigning cities and streets, incorporating urban greenery to provide more green open spaces (Honey-Rosés et al., 2020) and to achieve the co-benefits of climate adaptation (Sharifi, 2019a,b,c). Therefore, there were many debates in media regarding the link between the prevalence of COVID19 and urban design, though existing literatures do not indicate in detail how different design measures can affect the capacity of urban areas to respond effectively to the pandemic (Table 2). Planners are strongly recommending to keep supporting the development of urban areas firmly (Connolly et al., 2020b; Hamidi et al., 2020). According to the World Economic Forum (2015), three strategic recommendations can be provided to planners for the following purposes:

1. Incorporating spatial planning at the national and city levels: The main aim of such spatial planning for urban development would be to implement strategic urban infrastructure and housing level and to facilitate local and national governance.

2. Devising a static policy framework in urban infrastructure for internal investments: When investors will get ideal conditions for their investments, the national bodies should observe the availability of tools, e.g., private-public partnership to occupy investments for strategic urban infrastructure development.

3. Developing institutions to induct capacity building among people to enrich public-private partnerships: Different organizations are needed to come forward to support private groups to augment the job quality in order to attract more investments in building capacity. Developing countries especially need to undertake effective projects which will help to increase their interdisciplinary assistance potentiality, with the aim of strategic and resilient urban infrastructure development. 


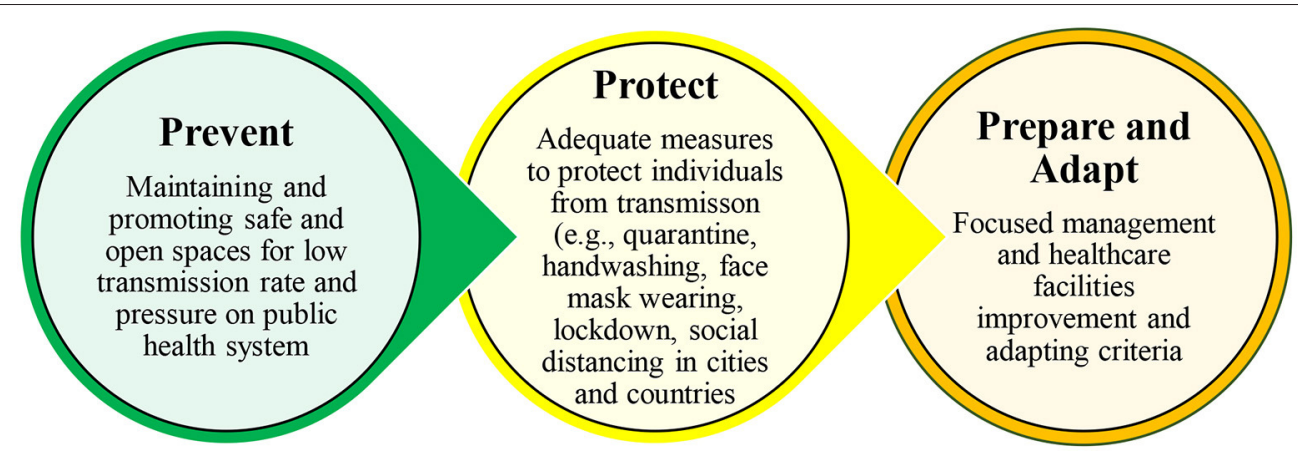

FIGURE 2 | Healthy pandemic-resilient strategy (three levels).

\section{Healthy Pandemic-Resilient Strategy and Conceptual Framework of DRM for the Pandemic-Resilient Urban Strategy}

In order to avoid transmission in cities, urban planning perspective can be segregated in three steps. A multilayer approach can be proposed based on resilient planning and strategies in cities. The strategy applies from larger- to smallerscale intervention criteria and also transforms to long- and shortterm action plans during disruptive events such as the pandemic. Figure 2 demonstrates a healthy pandemic-resilient strategy in three levels: prevent, protect, and prepare and adapt.

Resilience focuses on removing uncertainties through vulnerability assessment (Vaništa Lazarević et al., 2019; Lak et al., 2020), prevention, urban governance, and planning forms (Fekete et al., 2015). Resilience to the pandemic can be defined as the capacity of city environments to absorb a shock without a significant alteration in their function and structure (Zhou et al., 2020). The main advantage of introducing the term resilience for DRM is considered as a paradigm shift that has the potentiality to support the establishment of DRM strategies through conceptual and methodological implications (Fekete et al., 2015).

Therefore, a conceptual framework of DRM for the pandemicresilient urban strategy based on preparedness, mitigation, and response measures in three scales of housing, cities, and public spaces is demonstrated in Figure 3. The conceptual framework is established to address essential measures of an epidemic- and pandemic-resilient urban structure in two dimensions, physical and non-physical, that have a significant relationship with the three corresponding scales (Figure 3). The DRM conceptual framework incorporates an integrated diagram of $3 \times 3$ matrices of DRM phases (preparedness, mitigation, and response) in three spatial scales (housing, city, and public spaces) during the pandemic. The phases of DRM are required to be subjected to these three scales (housing, city, and public space scales) in a pandemic situation. These $3 \times 3$ matrices can be applied as a two-dynamics interconnected model in various conditions, thus connecting DRM phases and creating flexibility in cities to be resilient, though existing solutions focus on tackling infectious diseases to minimize economic loss. This framework can be significantly effective when there is combined participation of city residents. Citizens must follow certain guidelines (assuring public health, networking pattern, amenities support, and services) to control virus transmission rate in various levels (Omidi et al., 2020). In order to establish a conceptual framework, three phases of management are found in various aspects of a pandemic-resilient urban strategy. For each phase of the DRM, the framework has been demonstrated in detail to better assess the corresponding indicators. The demonstrated conceptual framework highlights physical (includes the city itself, surrounding areas, transportation access, land use, environmental factors, infrastructure, and so on) and nonphysical features (includes different aspects of socio-economic, cultural, and governance) of city-built environments (Lak et al., 2020) to combat the pandemic following the environmental and social health determinants. Existing literatures were followed for the development of the demonstrated conceptual framework. On the other hand, the conceptual framework was established to address essential measures of epidemic- and pandemicresilient urban structures in two dimensions-physical and non-physical-that have a significant relationship with the three corresponding scales (Figure 3). The DRM conceptual framework incorporates an integrated diagram of $3 \times 3$ matrices of DRM phases (preparedness, mitigation, and response) in three spatial scales (housing, city, and public spaces) during the pandemic.

\section{Response Phase}

In order to ensure an effective response to the pandemic, a surveillance approach of both software (knowledge and protocols) and hardware (public health system, public health infrastructure, and so on) must be incorporated. Different aspects of urban livelihood, such financial, social, political, physical, and natural assets, also needed to be changed through assessing the vulnerability context where pandemic is causing different stress and shocks and thus affecting urban groups. These shocks and stresses may arise from different dynamics operating from local and national levels. The response phase includes an early adaptation strategy of pandemic preparedness program. This phase involves several actions such as surveillance, response collaboration, trends in illness monitoring, disease or infection containment, and public communication system (Bell et al., 2009). Providing sufficient healthcare to sick people, 


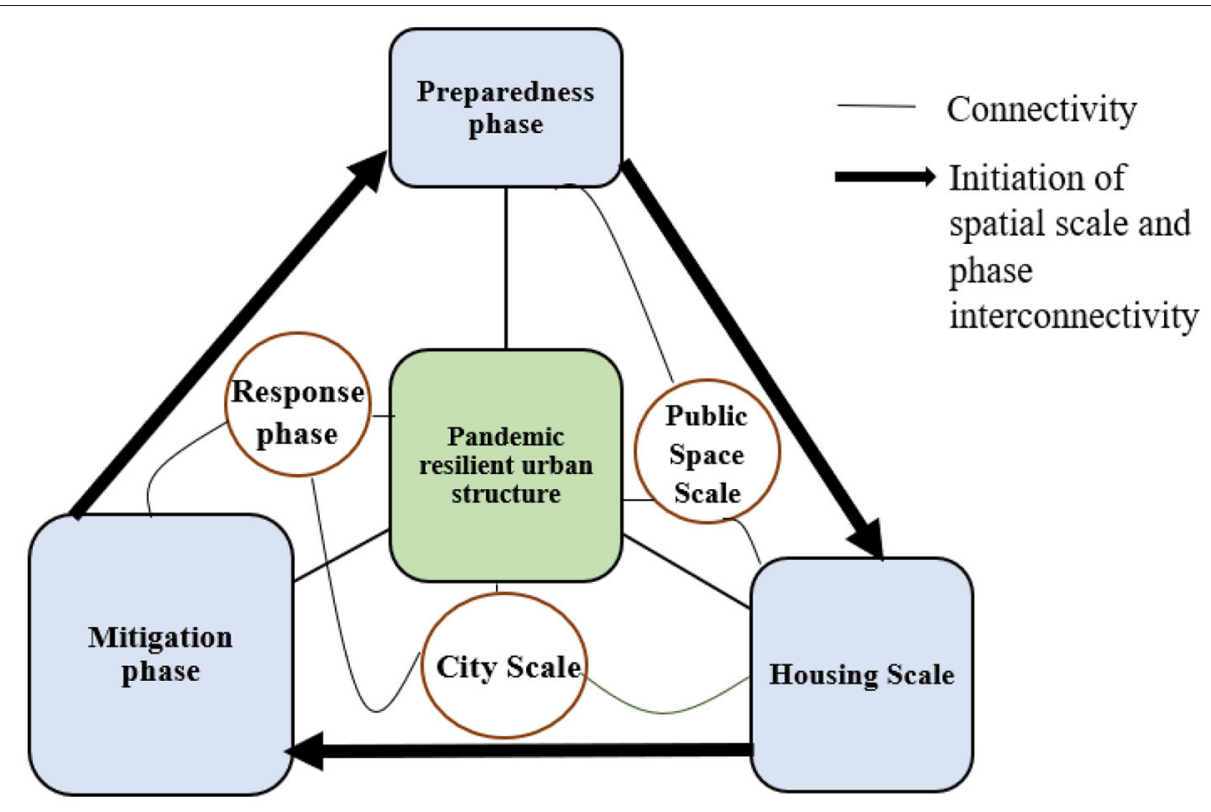

FIGURE 3 | The proposed framework of pandemic-resilient urban feature associated with three spatial scales and disaster risk management phases.

adequate ventilation facility of optimum humidity from 40 to $60 \%$, and filtering of interior air for sick families can be demonstrated in the housing scales. Depending on the importance of health in a pandemic situation at the housing and public space (Brizuela et al., 2019), the physical dimension of response plans can be incorporated through activities such as the following:

- improving infrastructures for a more effective use of smart technologies (e.g., mobile phones, applications, and Internet access) for better surveillance and monitoring of trends in illness trends through community centers at public space scales,

- influencing local people to control and restrict trips in public spaces or neighborhoods,

- seeking for public participation for better control at public space level,

- restricting the use of community gathering spots such as parks and playgrounds to follow social distancing measures,

- promoting walking considering physical distancing,

- frequently sanitizing public places and urban furniture in housing, public, and open spaces,

- sheltering homeless people in empty buildings such as schools (Rivera et al., 2020), restricting large public gatherings, and canceling programs,

- closing places of leisure such as theaters, museums, restaurants, and amusement parks

- creating a prevention area following EPA public health unit in public spaces,

- establishing a transparent information system to enhance public awareness, and

- providing local aid during social distancing to help vulnerable and marginalized groups.
The functional structure of the urban area can be enhanced by the following:

- helping urban and local medical services in various scales,

- identifying EPA-based public health service locations in cities,

- controlling airport activities and outgoing of passenger to the city,

- minimizing daily travels, thus reducing traffic congestion and air pollution,

- promoting integrated risk management,

- enhancing existing infrastructures, and

- enhancing knowledge on epidemics and pandemics.

However, establishing transportation, land use, and infrastructure planning information database can be proven effective to people in disruptive situations (Lee et al., 2020a,b; Mollalo et al., 2020). Monitoring and surveillance must be prioritized for proper identification of symptoms and necessary actions to be taken (Mollalo et al., 2020).

\section{Mitigation Phase}

The mitigation phase focuses on mitigating the urban issues in pandemics. In high-population-density areas, excessive connectivity, inadequate sanitation, and scarcity of water supply are contributing factors that are responsible for risk exposure. New technological approaches can be introduced in this phase for better management of epidemics, reducing misinformation on social networks. Informal technical networks can play a vital role in underlying concern regarding the preparedness stage (Lee et al., 2020a,b). To state clearly, in the sense of urban resiliency, the mitigation phase can be explained in two different aspects that are physical and non-physical dimensions (Garakani et al., 2020; Lak et al., 2020). 


\section{Physical Dimension}

Cities have certain characteristics that may play a crucial role in the mitigation and response phases to pandemics. Physical characteristics can be categorized as city-built environment, transportation access, land use, environment, infrastructure, and so on (Golkar, 2011).

City-Built Environment. Cities are very well-developed, so there is a high density of human infrastructures, e.g., commercial constructions, houses, roads, railways, and bridges. Urban areas usually refer to cities, suburbs, and towns. A city comprises the urban area itself along with the surrounding grounds. Urban forms determine the locations of housing and services in cities. Accordingly, they influence the transportation criteria of the people. The ratio of space and mass and density greatly influence the spread of the disease (Brizuela et al., 2019). The high population, unsafe housing, and over-gathering can also contribute to the rapid spread of the vector (Neiderud, 2015). However, inadequate social distancing can augment disease growth and outbreaks. Self-sufficiency and decentralized resource-efficient public spaces must be increased by creating more open spaces in nearby areas, taking into account the design and planning process. Limiting crowd formation in public spaces and cities may make cities more resilient to pandemics. At the city scale, a broader approach concerning population density needed to be adopted to prevent the virus from spreading (Chandra et al., 2013). Increased public or open spaces in nearby areas will help people in cities to socialize without maintaining social distancing. The EPA recommended that planning and design in city scale can also provide incentives to such approach. On the other hand, the distance between cities should be more convenient for preventing epidemic transmission (Lin et al., 2020b). Cross-regional coordination is important to reduce epidemic spreading in regions due to high population flow in different urban areas.

In housing scale, the characteristics of housing needed to be improved to prevent insect and vector proliferation, such as providing efficient filtering, sanitation, and ventilation system in designing homes and semi-public open spaces through designing sufficient space and shared sanitation facilities in the settlement. Resilient housing can prevent disease transmission in residential settlements (Neiderud, 2015).

Transportation and Infrastructure. The network of urban movement has a significant impact on mobility, which can be a key element in disease transmission. Moreover, properly qualified human mobility is essential in cities for identifying disease transmission dynamics and epidemic control measures (Hackl and Dubernet, 2019). Poor network design can cause traffic congestion, thus making obstacles for quick access to health centers. Crowded public transportation plays a pivotal role in increasing the virus' spreading rate (Elrahman and Meyer, 2019). Flexible bike- and walk-friendly pathways, with safe distancing, in public spaces must be ensured. These can be achieved through designing and planning transit neighborhood development that helps make uncrowded public transit with safe distancing and makes movement and public transportation safer.

\section{Non-physical Dimension}

The past and current COVID-19 pandemic has manifested and given people lessons that resilience should also be focused in socio-economic, cultural, and governance aspects that is a cost-effective characteristic of a public health system and provides support in addressing certain challenges. According to Djalante et al. (2020), resilience can foster science-based coordination and decision-making through ensuring buffer capacity even if a certain system is damaged. In over-crowded areas, poor road network people often suffer from a low hygiene level. Inequitable access to resources, education, and health facilities can impede social networks, thus affecting social capital. Thus, re-development may be needed to intensify social resilience during the pandemic (Tambo et al., 2018). Economic resilience enhancement should be considered as a perquisite to reduce socio-economic inequalities and to create a self-sufficient economy (Mollalo et al., 2020). Governance resilience can better manage the healthcare system for tackling the pandemic situation (Mollalo et al., 2020). Resiliency in governance can be described as the exact actions needed to be taken in creating a collaboration of effective communication, surveillance, and community protection through social distancing measures. It has the ability to enact efficiently to monitor and has surveillance systems to minimize the impacts (Tambo et al., 2018). Therefore, a pre-existing adaptation and pandemic plan may support intersectoral decision-making and the development of enhanced public communications. Planning support systems, decision support systems, and Geographic Information System (GIS) can facilitate governance to take decision more precisely during the pandemic (Mollalo et al., 2020). Smart cities can provide better management for pandemics:

- Through creating opportunities to identify and forecast outbreaks followed by data analysis: As a result, public security will be improved through enhanced infrared and facial recognition facilities, which will assist in research and surveillance (Omidi et al., 2020).

- In China, the government used various technologies, such as artificial intelligence, for better tracking and larger data analysis to combat the coronavirus and enhance the surveillance system, people's livelihood, and public security. The combination of infrared technologies with facial recognition can successfully detect individuals having a high temperature, even if an individual is wearing a mask (Allam and Jones, 2020).

\section{Preparedness Phase}

The preparedness phase aims on increasing the capacity of people to confront any outbreak. Some cities with previous high disease outbreaks have developed well-adopted surveillance systems using digital information (Tang et al., 2018). Contingency plans such as contributing links between healthcare facilities and the national-level authority can be achieved through proactive measures (Tay et al., 2010). Complex simulation processes can be performed in urban settings to model the disease transmission pattern and to determine effective health actions to prevent disease transmission (Ahn et al., 2018). This process can be useful 
for preparedness phase planning. These strategies can be involved in reducing human interaction during the pandemic. The main challenge that we are facing is how to maintain social life and sustain livelihood while reducing person-to-person interactions. These gaps can be filled out by virtual communication through technology at the local, regional, national, and global levels (Stier et al., 2020). This virtual social interaction can play a significant role in combat such as the pandemic situation. Following the impacts due to COVID-19, isolation and social distancing are crucial (World Health Organization, 2020). Meanwhile, residents in cities need to accept restrictions and limitation and to follow these measures. Planners can come forward to address and predict the necessary needs during the pandemic situation.

Public health and planning are complementary to each other. Health conditions are related to housing conditions such as insufficient access to water, poor environmental quality inside buildings, and exposure to infectious diseases, thus imposing such a significant health burden. Therefore, the present pandemic scenario has reflected the need of a cohesive approach in urban planning and design for public health. City residents can be vulnerable to communicable diseases due to urban fabric in high-population-density areas, where staying indoors, selfisolation, and physical distancing are much more challenging for a rigid city. However, residents should have easier access to better healthcare facilities. The advantages of a well-planned city include lesser commute times, low noise, clean air, and low consumption of energy and fossil fuels. In big cities, informal settlements should be focused accordingly to make an inclusive approach in order to improve life quality (housing, livelihood, essential services, sanitation, etc.). Therefore, the conversion of horizontal to vertical informal settlements does not solve the development crisis. It often creates misdiagnosis to the needs of the residents, which can be called home-grown neighborhoods.

\section{Leadership on Resilience Planning: Role of Chief Resilience Officers}

Leadership has an important connection with the proposed framework in order to bring resiliency in urban planning and design through the DRM approach and spatial scales. Leadership must be highlighted in order to think of the city's strategy on the frontline; resiliency in leadership is necessary. In this time of crisis, a resilient leadership is crucial to help urban areas by sharing knowledge and creating recovery plans to fight against the pandemic situation. In order to incorporate resilience in urban planning and design for the pandemic, leadership needs to be appointed, which can successfully segregate silos within the local government (Hu and Zheng, 2020). Leadership characteristics include chief resilience officers (CROs), who play a crucial forefront role. Several resilient programs, such as the 100 Resilient City program, have launched city CROs for communication and successful collaboration from different sectors. A compatible strategy must be developed to help cities confront different challenges such as health problems, economic downfall, climate change, and so on. Chief resilience officers have the ability to transgress and bring multiple sectors together because they can understand and address the city challenges in a prudent manner. Chief resilience officers can be great supporters in arranging funds and resources and would have the high-level priority to reach different sectors. In 100 Resilient City network, it has been surveyed that around $87 \%$ of chief resilient officers are engaged in their city's pandemic response and recovery approach. City leaders can also contribute significantly along with the CROs for a better analysis of the challenges and building a resilient future. Many cities (Austin, Texas, in the US and so on) worldwide have now pledged for CRO recruitment to carry on resilience responsibilities. In developing countries, the national policy level must focus on this issue most importantly. A good illustration of this has been found in such a way that the Ministry for Housing and Urban Affairs in India recently launched a framework on Climate Smart Cities Assessment to provide a distinct roadmap for cities to fight against challenges such as climate change and so on. More practical approach should be deployed for resilience measures in policy levels. The perception should be shifted to how resilience can be ensured rather than what and why resilience is important. Developed countries, such as Rotterdam, have launched a pandemic-resilient strategy for urban areas following COVID-19. COVID-19 has provided new insights but also resurrected the focus on resilience even harder than before in mid- and longterm pandemic response and recovery planning in cities. Seven qualities of resilience for a pandemic situation are reflectiveness, resourcefulness, redundancy, robustness, integrated, flexibility, and inclusiveness, which must be assessed equally in the response and recovery plan. The COVID-19 economic recovery plan should empower the economy and livelihood by focusing on green infrastructure and climate adaptation strategies. In cities, a set of principles should also be included to help in making decisions, generating ideas, and performing prioritizing actions. Those initiatives should contribute to a more resilient economy and society. A recent approach of "resilience scan" in cities can be also established in developing countries to support checklists of ensuring data of people encountering certain stresses and shocks, thus formulating resilience qualities in their planning and design. This toolkit can significantly help cities to combat multiple challenges efficiently. Within the framework, certain tools and collaborations are necessary for concentrating certain areas which are resilient: climate, circular economy, plastic pollution, waste management, and so on. Digital initiatives can also combine with resilience for cities' digitalization design to support resilience. CROs can improve such decision-making process by working in a cross-sectoral way. The collaboration of resilience with digital strategies is pivotal to cities for tackling both economic and social shocks and climate change. This pandemic situation has shed light on how to adopt a holistic approach to resilience planning and digitalization and their proper implementation. Resilience approaches protect cities from coming stresses-shocks and ensure a firm economic growth. In such cases, there are no alternatives of CROs.

\section{CONCLUDING REMARKS}

From a wider perspective, it can be concluded that active participation and a decentralized decision-making process can help to combat the pandemic situation successfully. It would be difficult to impose only one solution above all to the 
pandemic. This study mainly highlights a broader aspect of the conceptual framework of DRM approach in a prudent manner, where possible recommendations of three spatial scales (housing, city, and public spaces) are interconnected to augment the entire process of DRM phases (response, mitigation, and preparedness) in urban areas through creating a pandemic-resilient urban strategy with the purpose of achieving resiliency in urban planning and design. The role of CROs is indispensable to bring leadership in resilient urban planning and design, where they have the ability to facilitate the entire decision-making process, working in cross-sectoral areas to create concrete and viable urban plans and designs. The participation of both national- and local-level bodies plays a pivotal role in combating this pandemic situation. Sufficient safe health dispensation for people is needed to confront future shocks and stresses in a sustainable manner to get a healthier environment (Megaheda and Ghoneim, 2020). The study highlights the following:

1. To combat the pandemic situation, adaptation-based approached can be achieved successfully through following the resilience strategy in the DRM approach, continuing green practices, activities, and implementation and enhancing green buildings and access to safe water, though there will remain some uncertainties.

2. To assure a resilient approach, intensive community planning is needed to establish giving priorities on public health design, zoning, inclusive planning, and necessary advancements. Shedding light on this issue, integrated urban planning and design with disaster risk reduction and response approach can be very effective.

3. To maintain social interaction and health safety, safe public or open spaces need to be provided in designing a built environment, thus highlighting social disparities in cities.

4. Improved public infrastructures should be focused on how to make urban areas less vulnerable.

5. Policy planning must be improved; planners should enhance the capacity of urban areas to combat any pandemic situation.

\section{REFERENCES}

Ahn, I., Heo, S., Ji, S., Kim, K. H., Kim, T., and Lee, E. J. (2018). Investigation of nonlinear epidemiological models for analyzing and controlling the MERS outbreak in Korea. J. Theor. Biol. 437, 17-28. doi: 10.1016/j.jtbi.2017.10.004

Allam, Z., and Jones, D. S. (2020). On the coronavirus (COVID-19) outbreak and the smart city network: universal data sharing standards coupled with artificial intelligence (AI) to benefit urban health monitoring and management. Healthcare (Basel). 8:46. doi: 10.3390/healthcare8010046

Bell, D. M., Weisfuse, I. B., Hernandez-Avila, M., Del Rio, C., Bustamante, X., and Rodier, G. (2009). Pandemic influenza as 21 st century urban public health crisis. Emerg. Infect. Dis. 15, 1963-1969. doi: 10.3201/eid1512.091232

Boterman,W.R. (2020). Urban-rural polarisation in times of the corona outbreak? The early demographic and geographic patterns of the SARSCoV-2 epidemic in the Netherlands. Tijdschr. Econ. Soc. Geog. 111, 513-529. doi: $10.1111 /$ tesg.12437

Brizuela, N. G., García-Chan, N., Pulido, H. G., and Gerardo Chowell, G. (2019). Understanding the role of urban design in disease spreading. bioRxiv [Preprint]. 766667. doi: 10.1101/766667
6. Household space must be developed in such a way that people can be prepared for any disruptive situation, and more open/public spaces should be developed for people to better prepare for upcoming events.

Moreover, active participation from all sectors can act as the fundamental part of pandemic-RC in renewing urban virtual social interaction, spaces, and health and in incorporating local leadership. By ensuring enhanced capacity, preparedness, mitigation, and response measures for epidemics and pandemics in cities, the resilient urban form can be strengthened. Therefore, pandemic-resilient urban planning and design should incorporate a new concept of social aspect of public space. The emerging concept of social public space can change the pattern of human livelihood, such that how they interact and work in building a resilient environment. This emerging new concept is crucial for policymakers and city planners to strengthen existing systems and local capacities in order to control the transmission rate of infectious diseases in the coming days. In summary, a strategic, strong, and operational DRM approach and their implications along with three spatial scales (housing, city, and public spaces) in centralized decision-making is expected to contribute significantly to improving the urban planning and design in order to bring resiliency, thus combating the pandemic situation effectively. This study illustrates that the necessary preventive measures, decisions, and recommendations can be adopted by the national- as well as local-level bodies, both shortand long-term measures, on a pandemic-resilient urban planning perspective, though further study is needed to extract major lessons from a new normal and post-pandemic situation to fight against existing and coming challenges in urban areas.

\section{AUTHOR CONTRIBUTIONS}

SA: concept development and draft manuscript: FC: edit and review the manuscript: MR: concept development, content development, review manuscript, and overall supervision of the work. All authors contributed to the article and approved the submitted version.
Carmona, M. (2014). The place-shaping continuum: a theory of urban design process. J Urban Design. 19, 2-36. doi: 10.1080/13574809.2013.854695

Carteni, A., Di Francesco, L., and Martino,M. (2020). How mobility habits influenced the spread of the COVID-19 pandemic: results fromthe Italian case study. Sci. Total Environ. 741:140489. doi: 10.1016/j.scitotenv.2020.140489

Chandra, S., Kassens-Noor, E., Kuljanin, G., and Vertalka, J. (2013). A geographic analysis of population density thresholds in the influenza pandemic of 1918-19. Int J Health Geogr.12:9. doi: 10.1186/1476-072X-12-9

Connolly, C., Ali, S. H., and Keil, R. (2020a). On the relationships between COVID-19 and extended urbanization. Dial. Hum. Geogr. 10, 213-216. doi: 10.1177/2043820620934209

Connolly, C., Keil, R., and Ali, S. H. (2020b). Extended urbanisation and the spatialities of infectious disease: demographic change, infrastructure and governance. Urban Stud. 58, 245-263. doi: 10.1177/0042098020910873

Djalante, R., Shaw, R., and DeWit, A. (2020). Building resilience against biological hazards and pandemics: COVID-19 and its implications for the Sendai Framework. Prog. Disaster. Sci. 6:100080. doi: 10.1016/j.pdisas.2020.100080

Duggal, R. (2020). Mumbai's struggles with public health crises from plague to COVID-19. Econ. Polit. Wkly. 55, 17-20. 
Elrahman, S., and Meyer, M. (2019). Transportation and Public Health: An Integrated Approach to Policy, Planning, and Implementation. Amsterdam: Elsevier.

Fekete, A., Hufschmidt, G., and Kruse, S. (2015). Benefits and challenges of resilience and vulnerability for disaster risk management. Int. J. Disast. Risk Sci. 5, 3-20. doi: 10.1007/s13753-014-0008-3

Garakani, S. A., Lak, A., and Niyasati, M. (2020). Toward sustainable development in post-flood relocation of rural settlements in Iran. Int. J. Disast. Resil. Built. Environ. 11, 359-377. doi: 10.1108/IJDRBE-05-2019-0020

Golkar, K. (2011). Creating sustainable place: reflections on urban design theory. Uni. Shahid. Beheshti. Publ. 2011, 112-146.

Hackl, J., and Dubernet, T. (2019). Epidemic spreading in urban areas using agentbased transportation models. Futur Int. 11:92. doi: 10.3390/fi11040092

Hamidi, S., Sabouri, S., and Ewing, R. (2020). Does density aggravate the COVID19 pandemic?: early findings and lessons for planners. J. Am. Plan. Assoc. 2020, 495-509 doi: 10.1080/01944363.2020.1777891

Harapan, H., Itoh, N., Yufika, A., Winardi, W., Keam, S., Te, H., et al. (2020). Coronavirus disease 2019 (COVID-19): a literature review. J. Inf. Public Health 13, 667-673 doi: 10.1016/j.jiph.2020.03.019

Heymann, D. L., and Shindo, N. (2020). COVID-19: what is next for public health? Lancet 395, 22-28. doi: 10.1016/S0140-6736(20)30374-3

Honey-Rosés, J., Anguelovski, I., Chireh, V. K., Daher, C., Konijnendijk van den Bosch, C., Litt, J. S., et al. (2020). The impact of COVID-19 on public space: an early review of the emerging questions - design, perceptions and inequities. Cities Health 2020, 1-17. doi: 10.1080/23748834.2020.178 0074

Hu, Q., and Zheng, Y. (2020). Smart city initiatives: a comparative study of American and Chinese cities. J. Urb. Affairs 43, 504-525. doi: 10.1080/07352166.2019.1694413

Ji, W., Wang, W., Zhao, X., Zai, J., and Li, X. (2020). Cross-species transmission of the newly identified coronavirus 2019-nCoV. J. Med. Virol. 92, 433-440. doi: $10.1002 / j m v .25682$

Kinsman, J., Angrén, J., Elgh, F., Furberg, M., Mosquera, P. A., and Otero-Garcia, L. (2018). Preparedness and response against diseases with epidemic potential in the European Union: a qualitative case study of Middle East Respiratory Syndrome (MERS) and poliomyelitis in five member states. BMC Health Serv Res. 18:528. doi: 10.1186/s12913-018-3326-0

Kummitha, R. K. R., and Crutzen, N. (2017). How do we understand smart cities? An evolutionary perspective. Cities 67, 43-52. doi: 10.1016/j.cities.2017.04.010

Lak, A., Hasankhan, F., and Garakani, S. A. (2020). Principles in practice : toward a conceptual framework for resilient urban design. J. Environ. Plan. Manag. 1, 1-33. doi: 10.1080/09640568.2020.1714561

Lawton, M., and Nahemow, L. (2019). "Ecology and the aging process," in The Psychology of Adult Development and Aging, eds C. Eisdorfer and M. P. Lawton (Washington, DC: American Psychological Association), 619-674. doi: $10.1037 / 10044-020$

Lee, V. J., Aguilera, X., Heymann, D., Wilder-Smith, A., Lee, V. J., and Heymann, D. L. (2020a). Preparedness for emerging epidemic threats: a Lancet Infectious Diseases Commission. Lancet Infect Dis. 20, 17-19. doi: 10.1016/S1473-3099(19)30674-7

Lee, V. J., Ho, M., Kai, C. W., Aguilera, X., Heymann, D., and Wilder-Smith, A. (2020b). Epidemic preparedness in urban settings: new challenges and opportunities. Lancet Infect. Dis. 20, 527-529. doi: 10.1016/S1473-3099(20)30249-8

Lin, C., Lau, A. K. H., Fung, J. C. H., Guo, C., Chan, J. W. M., Yeung, D. W., et al. (2020a). A mechanism-based parameterisation scheme to investigate the association between transmission rate of COVID-19 and meteorological factors on plains in China. Sci. Total Environ. 737:140348. doi: $10.1016 /$ j.scitotenv.2020.140348

Lin, S., Qiao, Y., Huang, J., and Yan, N. (2020b). Research on the influence of effective distance between cities on the cross-regional transmission of COVID19. medRxiv. 1, 1-22. doi: 10.1101/2020.03.27.20044958

Lu, H., Stratton, C. W., and Tang, Y.-W. (2020). Outbreak of pneumonia of unknown etiology in Wuhan, China: the mystery and the miracle. J. Med. Virol. 92, 401-402. doi: 10.1002/jmv. 25678

Matthew, R. A., and McDonald, B. (2006). Cities under siege: urban planning and the threat of infectious disease. J. Am. Plan. Assoc. 72, 109-117. doi: $10.1080 / 01944360608976728$
Medda, F. (2012). Land value capture finance for transport accessibility: a review. J. Transp. Geogr. 25, 154-161. doi: 10.1016/j.jtrangeo.2012.07.013

Megaheda, N. A., and Ghoneim, E. M. (2020). Antivirus-built environment: lessons learned from Covid-19 pandemic. Sustain. Cities Soc. 61:102350. doi: $10.1016 /$ j.scs.2020.102350

Mills, C. E., Robins, J. M., and Lipsitch, M. (2004). Transmissibility of 1918 pandemic influenza. Nature 432, 904-906. doi: 10.1038/nature03063

Mollalo, A., Vahedi, B., and Rivera, K. M. (2020). GIS-based spatial modeling of COVID-19 incidence rate in the continental United States. Sci. Total Environ. 728:13884. doi: 10.1016/j.scitotenv.2020.138884

Mora, L., Bolici, R., and Deakin, M. (2017). The first two decades of smart-city research: a bibliometric analysis. J. Urban. Technol. 24, 3-27. doi: $10.1080 / 10630732.2017 .1285123$

Neiderud, C. J. (2015). How urbanization affects the epidemiology of emerging infectious diseases. Infect. Ecol. Epidemiol. 5:27060. doi: 10.3402/iee.v5.27060

Omidi, M., Maher, A., and Etesaminia, S. (2020). Lessons to be learned from the prevalence of Covid-19 in Iran. Med. J. Islam. Repub. Iran. 34, 398-399. doi: $10.34171 /$ mjiri.34.54

Osterholm, M. T. (2005). Preparing for the next pandemic. N Engl. J. Med. 352, 1839-1842. doi: 10.1056/NEJMp058068

Qiu, Y., Chen, X., and Shi, W. (2020). Impacts of social and economic factors on the transmission of coronavirus disease 2019 (COVID-19) in China. J. Popul. Econ. 33, 1127-1172. doi: 10.1007/s00148-020-00778-2

Ren, H., Zhao, L., Zhang, A., Song, L., Liao, Y., Lu, W., et al. (2020). Early forecasting of the potential risk zones of COVID-19 in China's megacities. Sci. Total Environ. 729:138995. doi: 10.1016/j.scitotenv.2020.138995

Rivera, J. D., Ceesay, A. A., and Sillah, A. (2020). Challenges to disaster risk management in The Gambia: a preliminary investigation of the disaster management system's structure. Prog Disaster Sci. 6:100075. doi: 10.1016/j.pdisas.2020.100075

Shammi, M., Bodrud-Doza, M., Towfiqul Islam, A. R. M., and Rahman, M. M. (2020). COVID-19 pandemic, socioeconomic crisis and human stress in resource-limited settings: a case from Bangladesh. Heliyon 6:e04063. doi: 10.1016/j.heliyon.2020.e04063

Sharifi, A. (2019a). Resilient urban forms: a macro-scale analysis. Cities 85, 1-14. doi: 10.1016/i.cities.2018.11.023

Sharifi, A. (2019b). Urban form resilience: a meso-scale analysis. Cities 93, 238-252. doi: 10.1016/j.cities.2019.05.010

Sharifi, A. (2019c). Resilient urban forms: a review of literature on streets and street networks. Build. Environ. 147, 171-187. doi: 10.1016/j.buildenv.2018.09.040

Sharifi, A. (2020). The COVID-19 pandemic: impacts on cities and major lessons for urban planning, design, and management. Sci. Tot. Environ. 749:142391. doi: 10.1016/j.scitotenv.2020.142391

Stier, A. J., Berman, M. G., and Bettencourt, L. M. A. (2020). COVID19 attack rate increases with city size. medRxiv 2020.03.22.20041004. doi: 10.1101/2020.03.22.20041004

Tambo, E., Ngogang, J. Y., Ning, X., and Xiao-Nong, Z. (2018). Strengthening community support, resilience programmes and inter-ventions in infectious diseases of poverty. East Mediterr. Health J. 24:598. doi: 10.26719/2018. 24.6.598

Tang, L., Bie, B., Park, S. E., and Zhi, D. (2018). Social media and outbreaks of emerging infectious diseases: a systematic review of literature. Am. J. Infect. Control. 46, 962-972. doi: 10.1016/j.ajic.2018.02.010

Tay, J., Ng, Y. F., Cutter, J., and James, L. (2010). Influenza A (H1N1-2009) pandemic in Singapore-public health control measures implemented and lessons learnt. Ann. Acad. Med. Singap.39, 313-312.

The World Bank Annual Report (2019). Ending Poverty, Investing in Opportunity. Washington, DC: World Bank. Available online at: https://openknowledge. worldbank.org/handle/10986/32333

Thoi, P. T. (2020). Ho Chi Minh City- the front line against COVID-19 in Vietnam. City Soc. 32. doi: $10.1111 /$ ciso. 12284

UNISDR (2015). Global Assessment Report on Disaster Risk Reduction 2015: Making Development Sustainable: the Future of Disaster Risk Management. Geneva: United Nations Int Strateg Disaster Reduct.

UNISDR U (2015). Sendai Framework for Disaster Risk Reduction 2015-2030. Geneva: United Nations Int Strateg Disaster Reduct.

Vaništa Lazarević, E., Keković, Z., and Antonić, B. (2019). In search of the principles of resilient urban design: implementability of the principles 
in the case of the cities in Serbia. Energy Build. 158, 1130-1138. doi: 10.1016/j.enbuild.2017.11.005

Wade, L. (2020). An unequal blow. Science 368, 700-703. doi: $10.1126 /$ science. 368.6492 .700

Wallace, D., and Wallace, R. (2008). Urban systems during disasters: factors for resilience. Ecol. Soc.13:18. doi: 10.5751/ES-02386-130118

World Economic Forum (2015). Inclusive Growth Report.

World Health Organization (2020). Considerations for Quarantine of Individuals in the Context of Containment for Coronavirus Disease (COVID-19): Interim Guidance.

Wu, J. T., Leung, K., and Leung, G. M. (2020). Nowcasting and forecasting the potential domestic and international spread of the 2019-nCoV outbreak originating in Wuhan, China: a modelling study. Lancet 395, 689-697. doi: 10.1016/S0140-6736(20) 30260-9

Xie, J., and Zhu, Y. (2020). Association between ambient temperature and COVID-19 infection in 122 cities from China.
Sci. Total Environ. 724:138201. doi: 10.1016/j.scitotenv.2020 138201

Zhou, C., Su, F., Pei, T., Zhang, A., Du, Y., and Luo, B. (2020). COVID-19: challenges to GIS with big data. Geogr Sustain. 1, 77-87. doi: 10.1016/j.geosus.2020.03.005

Conflict of Interest: The authors declare that the research was conducted in the absence of any commercial or financial relationships that could be construed as a potential conflict of interest.

Copyright (c) 2021 Afrin, Chowdhury and Rahman. This is an open-access article distributed under the terms of the Creative Commons Attribution License (CC BY). The use, distribution or reproduction in other forums is permitted, provided the original author(s) and the copyright owner(s) are credited and that the original publication in this journal is cited, in accordance with accepted academic practice. No use, distribution or reproduction is permitted which does not comply with these terms. 